\title{
Current Trends in
}

\section{Entomology and Zoological Studies}

\section{Efficiency of Spinosad in Oviposition Traps for Monitoring Arboviruses Vectors}

\author{
Cláudia Maria Fontes de Oliveira ${ }^{1}$ Cristina Maria de Menezes Torres ${ }^{2}$, Maria Alice Varjal de Melo-Santos ${ }^{1}$, Luciana Oliveira \\ Oliva $^{2}$, Cleide Maria Ribeiro de Albuquerque ${ }^{2 *}$
}

${ }^{1}$ Departamento de Entomologia, Instituto Aggeu Magalhães, Fundação Oswaldo Cruz. Av. Moraes Rego s/n, Cidade Universitária, Recife, Pernambuco, Brazil

${ }^{2}$ Laboratório de Invertebrados Terrestres, Departamento de Zoologia, Centro de Ciências Biológicas, Universidade Federal de Pernambuco. Curso de Pós-Graduação em Biologia Animal. Av. Moraes Rego s/n, Cidade Universitária, Recife, Pernambuco, Brazil

*Corresponding author: Cláudia Maria Fontes de Oliveira, Departamento de Entomologia, Instituto Aggeu Magalhães, Fundação Oswaldo Cruz. Av. Moraes Rego s/n, Cidade Universitária, Recife, Pernambuco, Brazil

Citation: Oliveira CMF, Menezes Torres CM, Melo-Santos MAV, Oliva LO, Albuquerque CMR (2018) Efficiency of Spinosad in Oviposition Traps for Monitoring Arboviruses Vectors. Curr Trends Entomol Zool Stds: CTEZS-110. DOI: 10.29011/ CTEZS-110. 000010

Received Date: 06 August, 2018; Accepted Date: 26 September, 2018; Published Date: 04 October, 2018

\begin{abstract}
Background dengue, chikungunya and Zika are vector borne diseases widely spread throughout the world affecting millions of people with Aedes spp. as the main vectors. Currently, vector control remains the most effective method for preventing diseases, particularly carried out with chemical pesticides leading to insecticide resistance in most mosquito populations' worldwide objective. We evaluated the larvicidal activity and persistence of tablet formulation of the biolarvicide spinosad (Natular $\left.{ }^{\mathrm{TM}} \mathrm{DT}\right)$ in ovitraps placed in shade and sunny environments, which established the basis for monitoring. Furthermore, the influence of spinosad on the choice of trap as an oviposition site and the potential of inhibition of hatchability in eggs were assessed methods. Three concentrations $-0.21,0.43$ and $0.87 \mathrm{~g} / \mathrm{L}$-were used in ovitraps installed and surveyed weekly for immatures results. Spinosad provided 8-17 weeks of control of Aedes spp. larvae. Ovitrap colonization ( $>90 \%)$ and egg density were recorded, indicating no repellent effect of the spinosad conclusion. The results provide evidence that the spinosad tablet formulation has a high persistence and larvicidal activity, particularly under unshaded conditions. Furthermore, the product does not interfere with the choice of the ovitrap as oviposition site by Aedes spp. female and may be indicated as an alternative for use in ovitraps.
\end{abstract}

Keywords: Saccharopolyspora spinosa; Biological control; Mosquito; Arboviruses

\section{Introduction}

Important arboviral diseases such as dengue (DENV), chikungunya (CHIKV) and Zika (ZIKV) that affect millions of people across the worlds have as main vectors Aedes mosquitoes, especially Aedes aegypti and Aedes albopictus [1,2]. Over the last 50 years, DENV and CHIKV have increased dramatically around the world causing high negative impact on public health in terms of morbidity, mortality and economic impact [1-5]. Recently, ZIKV has been expanded through the continental Americas causing outbreak of Zika virus disease [3], associated with neurological complications of microcephaly in newborns of ZIKV-infected mothers, as well as Guillain-Barré syndrome, particularly in Brazil [3]. In the absence of simple preventive methods and specific drugs, mosquito control is the primary means of preventing disease transmission and controlling epidemics [4]. In Brazil, the use of chemical insecticides, biological control, social interventions and environmental management remain the primary control methods for $A$. aegypti, the main vector of dengue, chikungunya and Zika in the country [5]. The extensive use of larvicides led to the emergence of populations of $A$. aegypti with different levels of resistance [6]. An alternative for the managing the resistance populations that has been the use of the biological larvicide based on the entomopathogenic bacteria Bacillus thuringiensis serovar 
israelensis (Bti) [6,7] and Saccharopolyspora spinosa [8,9]. The biological larvicide spinosad is a secondary metabolite from the aerobic fermentation of the soil bacterium Saccharopolyspora spinosa, composed of 2 tetracyclic neurotoxins (spinosyns A and D) $[8,9]$. The targets of this compound are the GABA and acetylcholine receptors, whose action mechanism leads to excitation of the nervous system, followed by paralysis and death of the larvae [10,11]. This biolarvicide, which acts by ingestion or contact, has been widely used in agriculture to control various pest species of the orders Diptera, Lepidoptera, Coleoptera, and Thysanoptera $[12,13]$. The low toxicity to humans and nontarget organisms [9-14] and lack of cross-resistance with other insecticides [15], have favored the use of spinosad in agriculture and more recently for the control of mosquitoes [16,17]. Although spinosad is found in liquid (emulsion concentrate) and solid (powder, granule, and tablet) formulations (Natular ${ }^{\mathrm{TM}}, 2013$ ), the majority of studies that have assessed its larvicidal effect against A. aegypti have used the liquid formulation [9-17]. Among the aspects that do not favor the liquid type of formulation of the biolarvicide spinosad are low stability in the environment and rapid degradation of the toxic components by exposure to sunlight [18]. Solid formulations are generally more stable, and some slowly release the active ingredient, prolonging the residual effect on the environment and favoring increased contact of the target organism to the toxic particles of the product [19]. The use of larvicidal products in oviposition traps has been fundamental for a long-term permanence of this tool during monitoring and control actions [6]. In the case of spinosad, it has been speculated by some authors that the time of exposure to the product in high concentrations in the trap would be a variable that may influence the hatchability of A. aegypti larvae [8-20]. In this sense a product with dual activitylarvicidal and ovicidal-would be beneficial as control measure. Thus, to evaluate the performance of spinosad in oviposition traps for Aedes spp., this study examined the following questions: (1) Does the use of high concentrations of spinosad affect the choice of oviposition site by Aedes spp. females? (2) What is the best relationship between the concentration of spinosad and the persistence of its larvicidal activity? (3) Does spinosad regulate the hatchability of Aedes spp. larvae?

Although there are already dengue vaccines, there is still no vaccine that is safe and effective for all people, so it is still an unmet need, since the population is not contemplated with a broad immunization for dengue [23]. Thus, vector control remains an important strategy to avoid disease.

\section{Materials and Methods}

\section{Period and Site of the Field Study}

Field tests occurred between January and October 2013, in Recife, State of Pernambuco and Northeastern Brazil. The experiments were conducted on the campus of the Federal University of Pernambuco, $8^{\circ} 3^{\prime} 7^{\prime \prime} \mathrm{S}$ and $34^{\circ} 56^{\prime} 59^{\prime \prime} \mathrm{W}$, in an area of $411,971 \mathrm{~m}^{2}$. This area is considered a strategic point because at the beginning of the experiments the level of Aedes spp. infestation in this area, estimated through positive ovitraps, was $97.5 \%(n=30)$. In addition, a large number of people (about 35,000) circulate in the campus daily, facilitating vector / host contact and consequently the possibility of virus transmission.

\section{Trap Model and Biological Larvicide}

Oviposition traps, called ovitraps, were constructed from plastic bottles (2 L) that were cut and painted black, adapted from the model described in Santos et al. [20]. Inside a bottle, a palette of Eucatex $(5 \times 12 \mathrm{~cm})$ was fixed vertically to serve as a substrate for Aedes spp. oviposition. The traps contained 1.5 L of water and spinosad tablet, Natular ${ }^{\mathrm{TM}}$ DT, containing $7.48 \%$ spinosyns in the following concentrations: $0.87 \mathrm{~g} / \mathrm{L}$ ( 1 tablet), $0.43 \mathrm{~g} / \mathrm{L}$ ( $1 / 2$ tablet), or $0.21 \mathrm{~g} / \mathrm{L}$ (1/4 tablet), provided by Clarke Mosquito Control Products.

\section{Experimental Design}

\section{Effect of Different Concentrations of Spinosad Tablets on Oviposition Site Selection}

At the beginning of the experiments, groups of 30 ovitraps for each experimental condition and untreated, totalizing 120 traps were used to evaluate the effect of different concentrations of spinosad on the choice of the traps as the oviposition site. Traps were placed in different buildings in areas completely protected from sunlight and rain (corridors and under stairs) $(n=60)$ or in places partially exposed to environmental elements under leaves on tree branches or in bushes (gardens) $(n=60)$. The presence and density of eggs in ovitraps were parameters used to evaluate the influence of different concentrations of spinosad on the choice of the trap as the oviposition site. For analysis, were considered only the eggs collected during the first 15 days after application of the product. The results were compared with those obtained from untreated ovitraps containing only water. To avoid the emergence of adults in the absence of larvicidal in untreated traps, the larvae were removed weekly and discarded.

\section{Persistence of Larvicidal Activity}

To evaluate the persistence (residual larvicidal activity) of spinosad tablet, 120 ovitraps were installed in a similar condition as described above in shade (sites completely protected from sunlight and rain) and unshaded (places partially exposed to environmental elements). In order to evaluate the residual activity of the products, the ovitraps were monitored at weekly intervals, considering the process of natural colonization of the area. After detection of the third-stage larvae (L3), the traps were monitored every 2 days to count and collect survivors in the L4 and pupal stages. 
The collected samples were monitored in the laboratory until the emergence of mosquitoes, to estimate the cumulative percentage of mortality. The volume lost by evaporation was replaced weekly. Residual larvicidal activity of the products was monitored until $\geq 80 \%$ inhibition of emergence. During the experimental period, the monthly average temperature and rainfall recorded in the study area were $28.4 \pm 2.6^{\circ} \mathrm{C}$ and $245.8 \pm 53.4 \mathrm{~mm}$, respectively.

\section{Effect of Spinosad on Hatchability}

Eggs present in palettes were examined under a stereomicroscope and classified as intact (sealed with normal appearance), open (without operculum), or withered (wrinkled and/or dehydrated). To avoid greater inaccuracies in the counting of larvae in the field traps, the hatching rate was based on eggs that still remained (closed sealed and wrinkled) in the paddles after 15 days. Inhibition of hatching of the larvae in the field was classified as low, moderate, or high whether the number of eggs intact and withered in the experimental groups were, respectively, 30\%, 50\%, or $80 \%$ higher than those in the control group. Differences in the mean number of these eggs were used to evaluate the effect of the concentration on hatching. To assess whether the apparently intact eggs retained hatchability after the period in the field, 1,500 eggs exposed to each spinosad concentration and the control were analyzed. The eggs were carefully removed from the pallets and placed in contact with water for seven consecutive days. The incubated larvae were observed after $48 \mathrm{~h}$ to determine the survival rate after hatching. Trials were performed in three replicates of 500 eggs each. Moreover, laboratory experiments were conducted to verify whether the effects of spinosad occurred early in the development of the embryo or after their formation. Groups of 50 eggs that were 1 day or 7-15 days old that originated from the F1 generation of the field population were exposed to different concentrations of the larvicide for 24,48 , or $72 \mathrm{~h}$. After each period, the eggs were dipped in water for a period of seven days and the hatching rate was recorded.

\section{Statistical Analyses}

One-way analysis of variance (ANOVA, $\alpha$ set to 0.05 ) with Tukey's HSD post-hoc correction on square-root transformation of the data and nonparametric Kruskal Wallis tests were applied for the comparative analysis, using BioEstat Version 5.3 software where $\mathrm{C}$ is the mean percentage survival of old L4 and pupae in the control group at a particular time, and $\mathrm{T}$ is the mean percentage of old L4 and pupae in the treated ovitraps in the same period. Numbers of Aedes spp. larvae and pupae were summed prior to analysis due to the low numbers of immature insects in some treatments. The persistence of the larvicide was estimated by calculating the inhibition of adult emergence with the formula of Darriet et al. [16].

$$
\% \mathrm{IE}=(\mathrm{C}-\mathrm{T}) / \mathrm{C} \times 100
$$

Residual larvicidal activity of the products was considered when the product promoted more than 80\% inhibition of emergence (IE \%) of exposed individuals [16]. Kruskal-Wallis test was conducted to verify whether there was a difference in values between time of persistence and place of traps installation (shady and unshaded sites). All data were previously tested for normality and homogeneity using Shapiro-Wilk and Bartlett test respectively

\section{Results}

\section{Selection of Ovitraps Containing Different Concentrations of Spinosad Tablets as Oviposition Site}

Total egg numbers per treatment ranged from 5,709 to 6,329 showing the average ( \pm standard error-SE) egg density of $135.86 \pm 21.59$ $(n=4,056)$ in untreated traps whereas in treated groups were $195.13 \pm 26.19(0.21 \mathrm{~g} / \mathrm{L}), 154.94 \pm 28.29(0.43 \mathrm{~g} / \mathrm{L}), 167.63 \pm 30.60$ $(0.87 \mathrm{~g} / \mathrm{L})$. These data do not differ significantly between treated and untreated trails ( F 3,120=1.674, $\mathrm{p}=0.174)$, indicating that spinosad would neither inhibit nor stimulate oviposition at the oviposition site. However, in general, the ovitraps containing spinosad had 19\% more eggs compared to that in the control.

\section{Persistence of Spinosad}

Mean numbers of Aedes spp. (larvae + pupae) registered in shady and unshaded traps along the study are shown in Table1. All three concentrations of the spinosad tablet showed residual larvicidal effects of $\geq 80 \%$ for 17-31 weeks, depending on the location of ovitraps (shaded or unshaded areas) (Table 1). The ovitraps treated with $0.21,0.43$, and $0.87 \mathrm{~g} / \mathrm{L}$ of the spinosad, in shaded areas, provided 9, 15 and 17 weeks of total control, respectively. In unshaded areas, the persistence of the product was lower, with the highest difference noted for $0.43 \mathrm{~g} / \mathrm{L}$ (Table 1). Even so, less than $13,3 \%$ of positive ovitraps showed low larval density ranging from $6.75 \pm 1.72$ to $12.5 \pm 1.15$, independent of the concentration and site of trap installation, and do not statistically differ along the weeks $(\mathrm{H}=9.7520, \mathrm{df}=5, \mathrm{p}=0.082)$. 


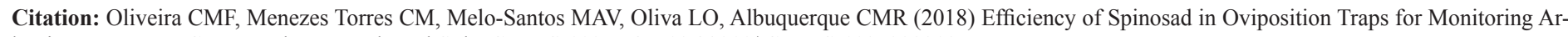
boviruses Vectors. Curr Trends Entomol Zool Stds: CTEZS-110. DOI: 10.29011/ CTEZS-110. 000010

\begin{tabular}{|c|c|c|c|c|c|c|}
\hline & \multicolumn{2}{|c|}{$0.21 \mathrm{~g} / \mathrm{L}$} & \multicolumn{2}{|c|}{$0.43 \mathrm{~g} / \mathrm{L}$} & \multicolumn{2}{|c|}{$0.87 \mathrm{~g} / \mathrm{L}$} \\
\hline & Unshaded & shady & Unshaded & Shady & Unshaded & shady \\
\hline \multirow{2}{*}{ IE $100 \%($ Mean \pm SE $)$} & 8 & 9 & 8 & 15 & 14 & 17 \\
\hline & 0 & 0 & 0 & 0 & 0 & 0 \\
\hline IE $\geq 80 \%$ Positive Traps (N) & 17 & 30 & 17 & 30 & 18 & 31 \\
\hline$($ Mean \pm SE) (range) & $\begin{array}{c}6.75 \pm 1.72^{\mathrm{a}} \\
(2-13)\end{array}$ & $\begin{array}{c}8.00 \pm 3.53^{\mathrm{a}} \\
(6-10)\end{array}$ & $\begin{array}{c}10.5 \pm 2.50^{\mathrm{a}} \\
(6-12)\end{array}$ & $\begin{array}{c}12.5 \pm 1.15^{\mathrm{a}} \\
(11-14)\end{array}$ & $\begin{array}{c}4.00 \pm 1.27^{\mathrm{a}} \\
(2-5)\end{array}$ & $\begin{array}{r}13 \\
-\end{array}$ \\
\hline
\end{tabular}

Table 1: Period (in weeks) of $100 \%$ and $\geq 80 \%$ IE. Mean $( \pm$ SE) positive trap of Aedes spp. live larvae (L4) and pupae in ovitraps containing $0.21,0.43$ and $0.87 \mathrm{~g} / \mathrm{L}$ of spinosad tablet installed in shaded and unshaded areas.

\section{Effect of Spinosad Tablets on Hatchability}

Total eggs sealed, opened and withered in the traps are shown in [Figure 1]. In the field, the percentage of eggs hatching in the control group was $39.4 \%$ and average $15 \%$ in the treated group, independent of the spinosad concentration. These data show a hatching inhibition rate in the treated groups $<30 \%$ compared to untreated groups corresponding to a low inhibition rate according to our classification. Variations in spinosad concentration did not influence hatching rate $(F 3,176=4.553, p=0.005)$. Sealed eggs retained hatchability after two weeks in the field in contact with spinosad. In the laboratory, 54.6\%, 64.6\%, and $64.0 \%$ intact eggs with no signs of morphological changes, hatched in the $0.21,0.43$, and $0.87 \mathrm{~g} / \mathrm{L}$ groups, respectively. In the control group, this percentage was $70.6 \%$. Analyzing the outcome of the Kruskal-Wallis test, $(\mathrm{H}=1.175, \mathrm{df}=3, \mathrm{p}=0.759)$ spinosad had no influence on hatchability. However, the hatched larvae from the eggs exposed to spinosad had a mortality rate of about $30 \%$ after $48 \mathrm{~h}$ of observation (Table 2). In this condition the mean percentage $( \pm \mathrm{SE})$ of dead larvae in comparison with total larvae in treated groups was $40.57 \%( \pm 1.0)$, while the equivalent value for larvae from untreated traps was nule (Table 2). In the laboratory, for eggs from the F1 generation of the field population placed in direct contact with spinosad, the hatching rate was approximately $25 \%$ lower than that in the control group, suggesting a reduced ovicidal effect (Table 3 ). In this experiment, neither the age of the egg ( 1 day or $7-14$ days old) ( $F 1,65=0.746, p=0.391)$ nor the exposure time $(24,48$, or $72 \mathrm{~h})(\mathrm{F} 2,65=2,167, \mathrm{p}=0.123)$ to the product at different concentrations influenced the hatching rate. However, a significant higher hatching rate was found in untreated than treated trials $(\mathrm{F} 3,68=31,58, \mathrm{p}<0,00005)$ (Figure 2).

\begin{tabular}{|c|c|c|c|c|}
\hline \multirow{2}{*}{$\%$} & \multirow{2}{*}{ Control } & \multicolumn{3}{|c|}{ Spinosad } \\
\cline { 3 - 5 } & & $0.87 \mathrm{~g} / \mathrm{L}$ & $0.43 \mathrm{~g} / \mathrm{L}$ & $0.21 \mathrm{~g} / \mathrm{L}$ \\
\hline Eclosion & $70.6 \pm 14.56$ & $64.0 \pm 13.86$ & $64.6 \pm 13.93$ & $54.6 \pm 12.81$ \\
\hline Mortality after 48h & 0 & $44.36 \pm 1.78$ & $42.00 \pm 1.34$ & $35.33 \pm 1.54$ \\
\hline
\end{tabular}

Table 2: Mortality of Aedes spp. larvae by the residual effect of spinosad impregnated in eggs collected in oviposition traps treated with different concentrations of tablet formulation.

\begin{tabular}{|c|c|c|c|c|c|c|c|}
\hline & & $24 \mathrm{~h}$ & Mean \pm SE & $48 \mathrm{~h}$ & Mean \pm SE & $72 \mathrm{~h}$ & Mean \pm SE \\
\hline \multirow{8}{*}{ Eggs 7-15 days } & \multirow{2}{*}{ Control } & \multirow{2}{*}{74} & $37.00 \pm 0.38$ & \multirow{2}{*}{62} & $31.00 \pm 0.62$ & \multirow{2}{*}{77.4} & $38.67 \pm 0.19$ \\
\hline & & & $(33-41)$ & & $(25-37)$ & & $(37-41)$ \\
\hline & \multirow{2}{*}{$0.87 \mathrm{~g} / \mathrm{L}$} & \multirow{2}{*}{48} & $24.00 \pm 0.11$ & \multirow{2}{*}{34} & $17.00 \pm 0.74$ & \multirow{2}{*}{52} & $26.00 \pm 0.11$ \\
\hline & & & $(23-25)$ & & $(11-21)$ & & $(2-27)$ \\
\hline & \multirow{2}{*}{$0.43 \mathrm{~g} / \mathrm{L}$} & \multirow{2}{*}{44} & $22.00 \pm 0.61$ & \multirow{2}{*}{38} & $19.00 \pm 0.80$ & \multirow{2}{*}{40.6} & $20.33 \pm 0.64$ \\
\hline & & & $(17-27)$ & & $(12-23)$ & & $(15-25)$ \\
\hline & \multirow{2}{*}{$0.21 \mathrm{~g} / \mathrm{L}$} & \multirow{2}{*}{35.4} & $17.67 \pm 0.69$ & \multirow{2}{*}{46} & $23.00 \pm 1.73$ & \multirow{2}{*}{43.4} & $21.67 \pm 0.51$ \\
\hline & & & $(13-23)$ & & $(21-14)$ & & $(17-27)$ \\
\hline \multirow{4}{*}{ Eggs 1 day } & \multirow{2}{*}{ Control } & \multirow{2}{*}{69.4} & $34.67 \pm 0.39$ & \multirow{2}{*}{70} & $35.00 \pm 0.35$ & \multirow{2}{*}{69.6} & $33.00 \pm 0.36$ \\
\hline & & & $(31-39)$ & & $(31-38)$ & & $(29-36)$ \\
\hline & \multirow{2}{*}{$0.87 \mathrm{~g} / \mathrm{L}$} & \multirow{2}{*}{50.6} & $25.33 \pm 0.96$ & \multirow{2}{*}{48.6} & $24.33 \pm 0.17$ & \multirow{2}{*}{49} & $17.67 \pm 0.55$ \\
\hline & & & $(20-35)$ & & $(23-26)$ & & $(13-20)$ \\
\hline
\end{tabular}


Citation: Oliveira CMF, Menezes Torres CM, Melo-Santos MAV, Oliva LO, Albuquerque CMR (2018) Efficiency of Spinosad in Oviposition Traps for Monitoring Arboviruses Vectors. Curr Trends Entomol Zool Stds: CTEZS-110. DOI: 10.29011/ CTEZS-110. 000010

\begin{tabular}{|c|c|c|c|c|c|c|}
\hline \multirow{2}{*}{$0.43 \mathrm{~g} / \mathrm{L}$} & \multirow{2}{*}{58.6} & $29.33 \pm 0.85$ & \multirow{2}{*}{45.4} & $22.67 \pm 0.14$ & \multirow{2}{*}{52} & $19.00 \pm 0.13$ \\
\cline { 3 - 3 } & & $(21-37)$ & $(22-24)$ & & $(18-20)$ \\
\hline \multirow{2}{*}{$0.21 \mathrm{~g} / \mathrm{L}$} & \multirow{2}{*}{50.6} & $25.33 \pm 0,47$ & \multirow{2}{*}{48.6} & $24,33 \pm 0.17$ & \multirow{2}{*}{36.6} & $18.33 \pm 0.07$ \\
\cline { 3 - 3 } & & $(22-30)$ & $(23-26)$ & $(18-19)$ \\
\hline
\end{tabular}

Table 3: Average percentage of larvae hatched from Aedes eggs in different ages exposed 1 to different concentrations of spinosad during 24,48 and 72 hours. Eggs were from the F1 2 generation of the field population.

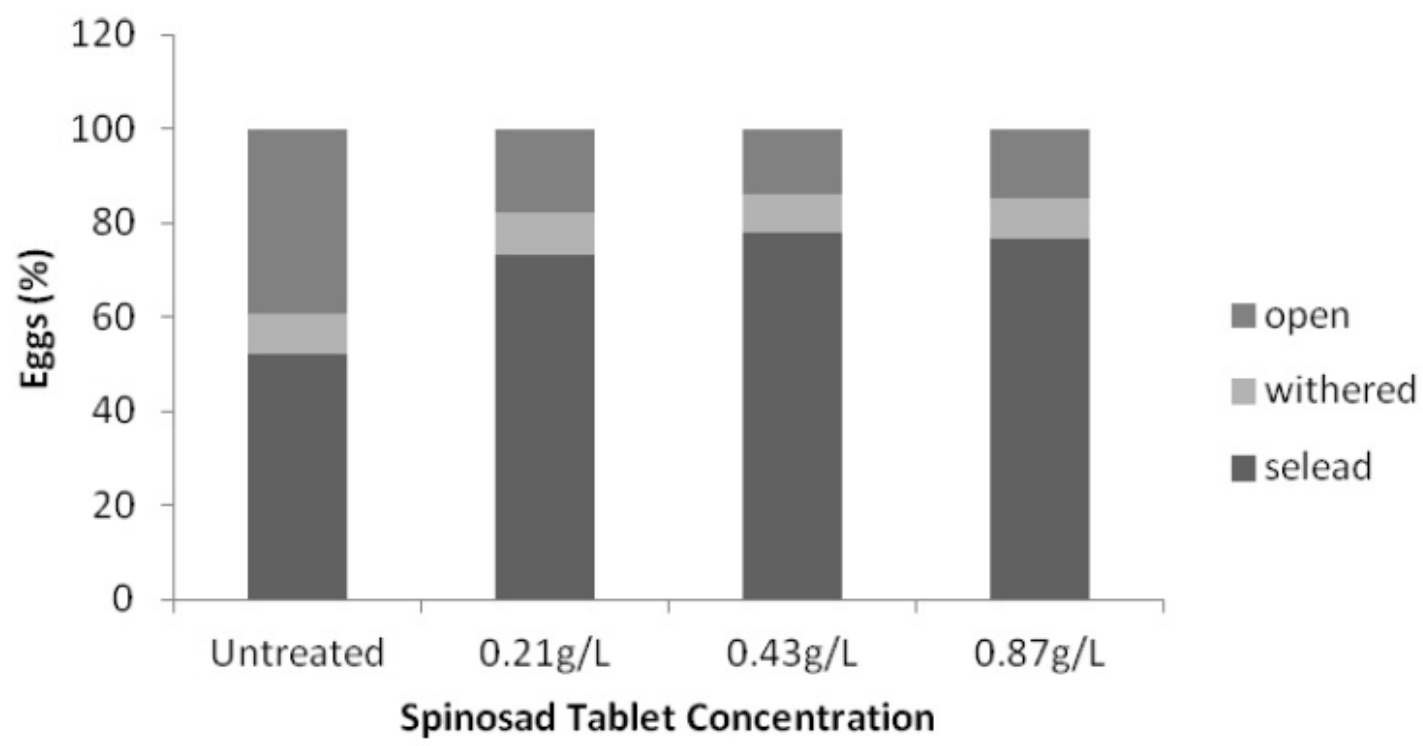

Figure 1: Aedes spp. egg hatchability inhibition (based on eggs morphological aspects) of different concentrations of spinosad tablet in field ovitraps.

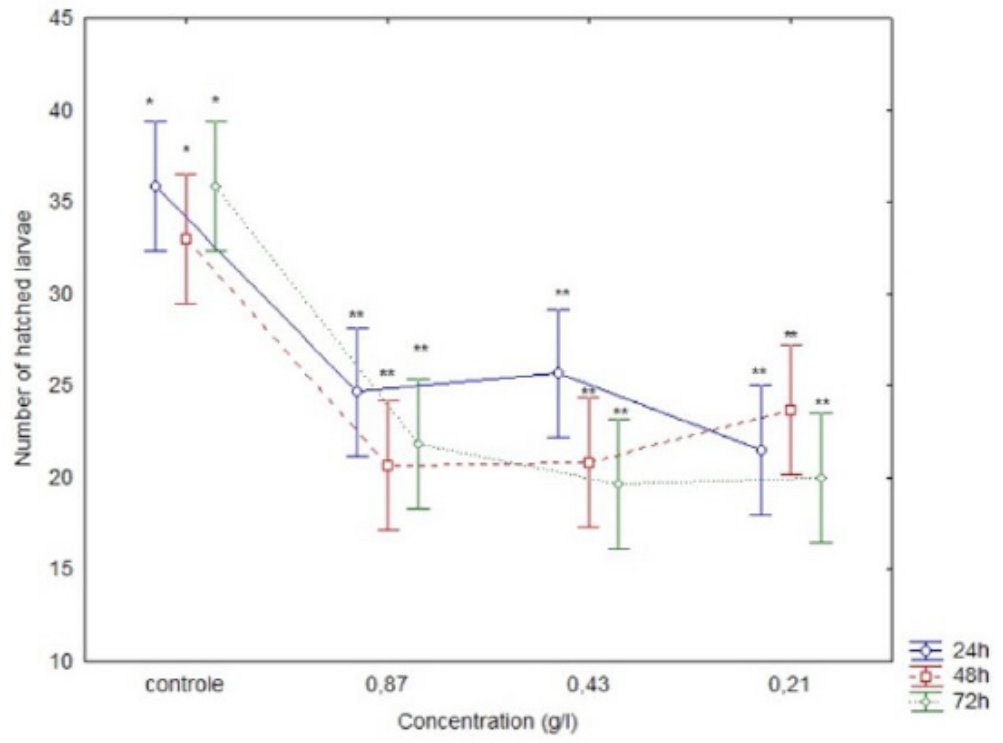

Figure 2: Graphic representation evidencing differences in hatching rate between the groups treated with different concentrations of spinosad tablet and untreated group. Lines followed by the same symbol $(* *)$ do not differ significantly, as tested by ANOVA, or from each other three following a Tukey's test $(\mathrm{P}<0.005)$. 


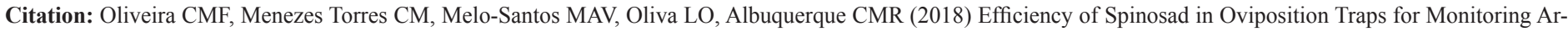
boviruses Vectors. Curr Trends Entomol Zool Stds: CTEZS-110. DOI: 10.29011/ CTEZS-110. 000010

\section{Discussion}

This study showed the performance of the larvicidal action of spinosad tablet (Natular ${ }^{\mathrm{TM}} \mathrm{DT}$ ) against Aedes spp. in ovitraps for population monitoring in urban areas. The use of spinosad at high concentrations did not influence the attractiveness of traps as oviposition sites for Aedes spp. Mosquito species. Furthermore, all concentrations were highly effective in preventing larval development. The residual larvicidal activity of the product ensured the permanence of the ovitrap in the field with the complete absence of live larvae for 8-17 weeks after a single treatment, despite the number of larvae had been similar in the traps installed in both environments. When installed in shady areas, the $0.43 \mathrm{~g} / \mathrm{L}$ concentration of spinosad tablet resulted in $100 \%$ control of larvae in the traps for 15 weeks, similar to that of the higher concentration $(0.87 \mathrm{~g} / \mathrm{L})$ at 17 weeks. Thus, in shaded areas, the use of $0.43 \mathrm{~g} / \mathrm{L}$ tablet concentration was the most appropriate. In situations where it is not possible to install the ovitraps in shaded areas, the use of $0.87 \mathrm{~g} / \mathrm{L}$ tablet concentration would be the most suitable, since this concentration showed longer persistence (14 weeks) in unshaded locations than that by the other concentrations ( 8 weeks). The effect of exposure to sunlight was also evident as it related to the persistence of the product with sufficient efficacy (IE\% $\geq 80 \%$ ) up to 18 weeks when the traps were placed in gardens and up to 31 weeks when placed in shaded areas. Sunlight has been shown as an adverse factor for the persistence of spinosad in liquid formulation [9,18,22]. Pérez et al. [22], used an emulsion of $10 \mathrm{mg} / \mathrm{L}$ of spinosad in ovitraps installed in a cemetery in Mexico and reported 99.7\% loss of toxicity of spinosad when exposed to direct sunlight for 20 days, while containers that remained in shaded areas showed $92 \%$ loss of toxicity after 90 days. The data are supported by the observations of Cleveland et al. [18], of the rapid photodegradation of spinosyns in the aquatic environment, with a half-life of $<1$ to 2 days. According to these authors, photolysis would be the main route of degradation of spinosyns in aquatic systems. Our study findings confirm the observations; however, the effect was minimized, possibly due to the greater stability of the solid tablet formulation and its characteristic slow release of spinosyns. Our results show a persistence of larvicidal activity, at least two times lower than spinosad in unshaded environments, although the traps were not directly exposed to sunlight. Further studies need to be performed to evaluate the effect of direct sunlight on the spinosad tablet. It is plausible suppose that a greater stability of the solid formulation occurs due to its characteristic of slow release of spinosyns the persistence of larvicidal effect of low spinosad concentration $(0.21 \mathrm{~g} / \mathrm{L})$ to $100 \%$ of the exposed individuals was at least 8 weeks, even under adverse conditions, revealing its high potential for use in ovitraps. In our study, a complete larval control was obtained for 8 - 14 weeks $\left(0.21 \mathrm{~g} / \mathrm{L}-0.87 \mathrm{~g} / \mathrm{L}\right.$, Natular ${ }^{\mathrm{TM}} \mathrm{DT}, 7.48 \%$ a.i) in unshaded sites. In a similar environment, Marina et al. [9], assessed the performance of spinosad (480SC Tracer; Naturalyte Insect
Control, Dow Agrosciences LLC- 48\% a.i) in liquid formulation at oviposition traps during the dry season in Mexico, and found that spinosad persisted for 6 or 8 weeks with complete larval control at concentrations of 1 and $5 \mathrm{mg} / \mathrm{L}$, respectively. The data suggest that the solid formulations tend to improve the field performance of the bacterial control agents, revealing its high potential for use in ovitraps. In addition, the use of the tablet in ovitraps implies the reduction of effort associated with the application and transportation of the product in the field, as well as in reducing the frequency of inspection of traps by health agents, which are aspects that could promote the use of spinosad. Although spinosad tablet formulation showed a significantly higher hatching inhibition rate than control, this difference refers to less than $30 \%$ of the eggs analyzed. Therefore, more than $70 \%$ of the eggs remained with possible hatchability hability. It was expected that the ovicidal effect of the product would be potentialized by increasing the concentration which was not confirmed in this study, suggesting that spinosad tablet, even at highest concentrations tested, has low inhibition hatching activity. The results corroborate those by Perez et al. [22], for liquid spinosad (480SC Tracer), which was also used in high concentrations ( 5 and $20 \mathrm{mg} / \mathrm{L}$ ) presenting a hatching rate similar to controls. Argueta et al. [20], also showed low ovicidal activity for the liquid formulation (480SC Tracer), with the mean percentage of inhibition of hatching of $A$. aegypti ranging from $6.8 \%$ with $1 \mathrm{mg} / \mathrm{L}$ to $8.2 \%$ with $10 \mathrm{mg} / \mathrm{L}$ of the product. In our study, about $30 \%$ mortality was observed for larvae hatched from the eggs exposed to the spinosad in the ovitraps, suggesting the presence of larvicidal residues impregnated on the surface of the eggs in amounts capable of promoting additional mortality. To our knowledge, this feature has not been described for spinosad until now.

\section{Conclusion}

To conclude, spinosad even at high concentrations has no repellent activity in ovitraps for Aedes spp, but shows extended residual larvicidal activity, particularly in ovitraps installed in shaded areas. Further, in shaded areas, a complete absence of larvae in the ovitraps can be maintained for up to 17 weeks. It is suggested that the spinosad tablet, particularly at $0.43 \mathrm{~g} / \mathrm{L}$, can be used in ovitraps for monitoring in Aedes spp. control programs, because of its high potential larvicidal and operational advantages namely ease of application and prolonged persistence. Other advantages attributed to spinosad such as low toxicity to non-target organisms [14] and an action mechanism different from chemical larvicides makes this a more environmentally safe product, with high potential for use in the population control of mosquito species and a candidate for the management of populations resistant to chemical insecticides. These results suggest a potential utilization of spinosad tablet for the control of Aedes vectors of diseases such as dengue, Zika and chikungunya. 
Citation: Oliveira CMF, Menezes Torres CM, Melo-Santos MAV, Oliva LO, Albuquerque CMR (2018) Efficiency of Spinosad in Oviposition Traps for Monitoring Arboviruses Vectors. Curr Trends Entomol Zool Stds: CTEZS-110. DOI: 10.29011/ CTEZS-110. 000010

\section{Conflict of Interests}

The authors declare that there is no conflict of interests regarding the publication of this paper.

\section{Acknowledgement}

The authors thank the Clarke Mosquito Control for the supply of larvicide NatularTM DT and the National Council for Scientific Development (CNPq) for the Research Productivity grant to Dr. CMR Albuquerque (\# 307759 / 2015-6).

\section{References}

1. Weaver SC (2014) Arrival of chikungunya virus in the new world: prospects for spread and impact on public health. PLOS Neglected Tropical Diseases 8: 2921

2. Chouin-Carneiro T, Vega-Rua A, Vazeille M, Yebakima A, Girod R, et al. (2016) Differential susceptibilities of Aedes aegypti and Aedes albopictus from the Americas to Zika virus. PLOS Neglected Tropical Diseases, 10: 0004543.

3. Ladhani SN, O'Connor C, Kirkbride H, Brooks T, Morgan D (2016) Outbreak of Zika virus disease in the Americas and the association with microcephaly, congenital malformations and Guillain-Barré syndrome. Archives of Disease in Childhood 101: 600-602.

4. Washington DC, PAHO (2016) Provisional considerations for the care of pregnant women in settings with high Zika virus circulation: document for health care professionals 1-31.

5. Zara ALSA, Santos SM, Fernandes-Oliveira ES, Carvalho RG, Coelho GE, et al. (2016) Estratégias de controle do Aedes aegypti: uma revisão. Epidemiologia de Serviço de Saúde 2: 391-404.

6. Regis LN, Acioli RV, Silveira JC, Melo-Santos MAV, Souza WV, et al. (2013) Sustained Reduction of the dengue vector population resulting from an integrated control strategy applied in two Brazilian cities. PLoS One 7: 67682.

7. Araújo AP, Diniz DFA, Helvécio E, Barros RA, Oliveira CMF, et al. (2013) The susceptibility of Aedes aegypti populations displaying temephos resistance to Bacillus thuringiensis israelensis: a basis for management. Parasites \& Vectors 6: 297-306.

8. Romi R, Proietti S, Di Luca M, Cristofaro M (2006) Laboratory evaluation of the bioinsecticide spinosad for mosquito control. Journal of the American Mosquito Control Association 22: 93-96.

9. Marina CF, Bond JG, Casas M, Muñoz J, Orozco A, et al. (2011) Spinosad as an effective larvicide for control of Aedes albopictus and Aedes aegypti, vectors of dengue in southern Mexico. Pest Management Science 67: 114-121.

10. Watson GB (2001) Actions of insecticidal spinosyns on g-aminobutyric acid responses from small-diameter cockroach neurons. Pesticide Biochemistry and Physiology 71:20 -28.

11. Orr N, Shaffner AJ, Richey K, Crouse GD (2009) Novel mode of action of spinosad: Receptor binding studies demonstrating lack of interaction with known insecticidal target sites. Pesticide Biochemistry and Physiology 95: 1-5.
12. Subramanyam B, Toews MD, lleleji KE, Maier DE, Thompson GD, et al. (2007) Evaluation of spinosad as a grain protectant on three Kansas farms. Crop Protection 7: 1021-1030.

13. Allal-Benfekih L, Aoudia B, Mostefaoui H, Belguendouz R (2013) Comparative evaluation of the toxicity of lambda cyhalothrin and spinosad on the insect pests and auxiliary fauna in an orange orchard of the central Mitidja (Blidean Atlas, Algeria). American-Eurasian Journal of Sustainable Agriculture 7: 21 - 26.

14. Williams T, Valle J, Viñuela $E$ (2003) Is the naturally-derived insecticide spinosad compatible with insect natural enemies?. Biocontrol Science And Technology 13: 459 -475.

15. Darriet F, Duchon S, Hougard JM (2005) Spinosad: a new larvicide against insecticide-resistant mosquito larvae. Journal of the American Mosquito Control Association 21: 495-496.

16. Darriet F, Marcombe S, Etienne M, Yébakima A, Agnewet $P$, et al. (2010) Field evaluation of pyriproxyfen and spinosad mixture for the control of insecticide resistant Aedes aegypti in Martinique (French West Indies). Parasites and Vectors 3: 88-96.

17. Marina CF, Bond JG, Muñoz J, Valle J, Chirino N, et al. (2012) Spinosad: a biorational mosquito larvicide for use in car tires in southern Mexico. Parasites \& Vectors $5:$ 95-104.

18. Cleveland CB, Bormett GA, Saunders DG, Powers FL, Mcgibbon AS (2002) Environmental fate of spinosad. 1. Dissipation and degradation in aqueous systems. Journal of Agricultural and Food Chemistry 50: 3244-3256

19. Couch TL, Charles JF, Delécluse A, Nielsen-LeRoux C (2000) Industrial fermentation and formulation of entomopathogenic bacteria"in (Eds), Entomopathogenic Bacteria: from Laboratory to Field Application. First edition, Kluwer Academic Publishers, Dordrecht, 297-314.

20. Argueta AL, Valle J, Marina CF (2011) Efectos ovicida y larvicida del spinosad en Aedes aegypti (Diptera: Culicidae). Revista Colombiana de Entomología 37: 269 - 272.

21. Santos EM, Melo-Santos MAV, Oliveira CMF, Correia J, Albuquerque CMR (2012) Evaluation of a sticky trap (AedesTraP), made from disposable plastic bottles, as a monitoring tool for Aedes aegypti populations. Parasites \& Vectors 5: 195-204.

22. Pérez CM, Marina CF, Bond JG, Rojas JC, Valle J, et al. (2007) Spinosad, a naturally derived insecticide, for control of Aedes aegypti (Diptera: Culicidae): efficacy, persistence, and elicited oviposition response" Journal of Medical Entomology, 44: 631-638.

23. Ramasamy V, Arora U, Upasana S, Rahul P, Poddar A, et al. (2018) A tetravalent virus-like particle vaccine designed to display domain III of dengue envelope proteins induces multi-serotype neutralizing antibodies in mice and macaques which confer protection against antibody dependent enhancement in AG129 mice. PLoS Neglected Tropical Diseases 12: 1-27. 